SarzamArobi', Jamiun Naher², Tanjir Rashid Soron*3

\title{
Impact of River Bank Erosion on Mental Health and Coping Capacity in Bangladesh
}

\author{
'MSc. in Psychology, University of Dhaka, Dhaka-1000 \\ ${ }^{2}$ Asst. Professor, Department of Psychology, University of Dhaka, Dhaka-1000 \\ ${ }^{3}$ Managing Director, Telepsychiatry Research and Innovation Network Ltd \\ *email: tanjirsorondagmail.com
}

DOI: $10.2478 / g p-2019-0011$

Received: 8 April 2019; Accepted: 23 May 2019

\begin{abstract}
Objectives: Riverbank erosion is a regular phenomenon that displaces millions of people every year worldwide. More than 100,000 people are displaced due to river erosion every year in Bangladesh. People have to resettle in a different place leaving behind their property and familiar environment. This transformation with economic crisis acts as a major stressor for the persons and their families. However, people may adapt different strategies to adapt this difficult situation and keep themselves healthy. They might have higher coping skills due to what they had to endure. This study aimed to find out the difference in the mental health status and coping strategies among the river bank erosion affected and non-affected people in Bangladesh

Methods: We interviewed 100 adult respondents, of whom 50 had been affected and 50 had never been affected by river erosion in Bangladesh. All the participants completed self-report sociodemographic questionnaires; their mental state was evaluated with the Bangla version of the General Health Questionnaire-12 (GHQ-12) and the coping was measured using the COPE scale.

Result: The mental health well-being score of the affected group was significantly lower than the non-affected group. However, accounting for gender, income and age, the affected group had lower mean score in coping (55.86) then the non-affected group (64.04). However, the difference was not statistically significant.

Conclusions: Riverbank erosion is a major natural disaster in Bangladesh that makes people vulnerable to mental disorder. However, it receives less attention; we hope this study will stimulate future researcher to explore mental state and coping mechanism in multiple perspectives and develop evidence-based service for them.
\end{abstract}

\section{Keywords}

Riverbank erosion, mental health, coping strategy, Bangladesh, resilience

\section{INTRODUCTION}

Impact of disaster on health has long been discussed in the scientific community. Natural disasters affect millions of people physically and psychologically all over the world (Norris, et al., 2002) and the consequences are widespread and may be long term. About $30-50 \%$ of the disaster affected people suffer from moderate to severe psychological distresses (WHO, 2017) due to high exposure to the trauma, experiencing injury or death of loved one and reduced social support (Brooks, et al., 2018). Among the disaster victims, post-traumatic stress disorder (PTSD), major depressive disorder (MDD), anxiety, phobia, prolonged grief and behavioural problems are common (Neria, et al., 2009; Norris \& Elrod, 2006; Norris, et al., 2002). Among the different types of natural disasters, river bank erosion is less discussed in the social, political or scientific community as it is happening most of the time somewhere in the world.

Bangladesh is a riverine country in the Southeast Asia where natural disasters are a very common phenomenon due to its geo territorial location, land characteristics, multiplicity of rivers and monsoon climate (Yeasmin \& Islam, 2011). As a result, river bank erosion is one of the major devastating ongoing natural disaster for the country (Islam \& Rashid, 2011). Large number of people in this region live along the rivers and are more likely to be affected by bank erosion (Das et al., 2017). The 
affected people face displacement, economic loss, physical and psychosocial problems that shift them in economic downwards. All these stressors put their coping capacity and mental health in a stressful condition and the insufficient coping behaviour under chronic stress lead to mental health problems (Mohr, et al., 2013) and attempts to successful suicide have been reported among the victims. Though Karatsoreos and Mcewen (2013) found the coping capacity was strongly associated with a person's previous experience and neurophysiological adaptation of brain. That explains why every person being exposed to natural disasters will not suffer from mental health problem. Most of the affected people that encounter the catastrophic event tried to resist or recover (Norris, et al., 2008). They used different coping mechanisms to adjust with daily life and new environment. The frequent exposure in natural disaster made people of Philippines resilient by adapting specific coping mechanisms to mitigate the worst effects of disasters (Bankoff, 2007). Keya and Harun (2007) evaluated the psychological state of river erosion affected women amongst a small number of people in one of the affected site in Bangladesh. The study revealed that women used different types of coping mechanisms to reduce their stress - by reappraisal and seeking social support, sometimes, using less confrontive coping - which is a sign of constructive adaptation strategy. The scientific evidence on the psychological impact of disaster and it's coping capacity of the river bank erosion is almost absent in Bangladesh. In the current study, we aimed to fill this gap in the knowledge by evaluating the impact of mental health wellbeing and coping mechanisms of the people. We hope this research will help in better understanding of the coping strategies and will provide initial evidence for future research and planning.

\section{MATERIALS AND METHOD}

This study was conducted in two neighbouring villages adjacent to the mighty river Padma in the mid-western region in Bangladesh, close to the Indian border. One village is Philipnagar (5156 inhabitants) and the other is Maricha (2920 inhabitants) about 4 kilometres apart in the Daulatpur Upazilla of the Kushtia District. According to the Bangladesh disaster report (2013), Philipnagar is one of the most severely affected areas by river erosion, where the river Padma has engulfed 1000 houses and 1500 hectares of agricultural lands and imposed a severe psychological distress among the victims. For this study, we aimed to evaluate the coping capacity and mental health of 100 residents in this area living permanently for more than 15 years and having no previous diagnosed mental disorders. Participants having physical illness making it difficult for them to communicate were excluded from the study. To have a total of 100 respondents, we aimed to include 50 respondents from Philipnagar, who were victims of river erosion and had lost their land or household, and the another 50 respondents were randomly selected from Maricha, who never experienced river bank erosion. To reach this desired number, we approached 103 participants. However, 3 participants refused to participate in the study due to their busy schedule. The respondents were recruited randomly and their participation was voluntary; no financial benefit was provided for the participation in this study. The participants were informed of the purpose of the present study and necessary rapport was established before administering the questionnaires. The respondents were instructed to read the items of the scales attentively and to respond rapidly. All the necessary clarifications were made regarding the items. They were asked to put tick $(\sqrt{ })$ marks in the appropriate boxes. They were also requested not to leave any item in the questionnaire, and were told that there was no right or wrong answer and no time limit for answering. The respondents were requested to complete the following questionnaires:

1. Demographic and Personal Information Questionnaire (age, gender, education, income, marital status, occupation and socio-economic status, etc.).

2. Bangla version of the General Health Questionnaire-12 (GHQ-12). The original GHQ was developed by Goldberg (1978) as a measure of the current mental health status that has been widely used in different cultures and different settings (Montazeri et al., 2003). It was translated and adapted in Bengali (Ilyas, 2002). A high General Health Questionnaire-12 score indicated reporting of more symptoms, that is, lower mental health.

3. The COPE scale (originally developed by Carver, Scherier and Weintrauh, 1989) adapted by Rahman and Islam (2011). The COPE scale is theoretically based 60 items on self-report measures. Here participants are instructed to report what they usually do when they are dealing with stress. The scale assesses the three factors as: (a) Problem focused, b) Emotion focused and c) Dysfunctional coping strategies of the participants. The internal consistency of the Bangla scale was acceptable.

After completing the questionnaire, they were thanked for their cooperation and assured that their answers would be completely confidential and these would be used for research purpose only. To compare the general health as a function of the participants' coping strategies for affected and non-affected people, we used independent sample t-test, cross tabulation and frequency. The data were analysed using the Statistical Package for Social Sciences (SPSS) Software version-20. 
Table 1. Socio-demographic information of the respondents of the two sites

\begin{tabular}{|c|c|c|c|c|c|}
\hline \multicolumn{2}{|l|}{ Criterion } & \multicolumn{2}{|l|}{ Affected } & \multicolumn{2}{|l|}{ Non-affected } \\
\hline & & \multirow{2}{*}{\begin{tabular}{|l} 
Frequency (n) \\
22
\end{tabular}} & \multirow{2}{*}{$\begin{array}{l}\text { Percentage (\%) } \\
44.0\end{array}$} & \multirow{2}{*}{$\begin{array}{l}\text { Frequency (n) } \\
26\end{array}$} & \multirow{2}{*}{\begin{tabular}{|l|} 
Percentage (\%) \\
52.0
\end{tabular}} \\
\hline Gender & Male & & & & \\
\hline & Female & 28 & 56.0 & 24 & 48.0 \\
\hline \multirow[t]{3}{*}{ Daily income } & 5 USD and above & 2 & 4.0 & 12 & 24.0 \\
\hline & 2-5 dollar/day & 36 & 72.0 & 30 & 60.0 \\
\hline & Less than 2 USD/day & 12 & 24.0 & 8 & 16.0 \\
\hline
\end{tabular}

Table 2. Mean COPE score of the riverbank erosion affected and non-affected group

\begin{tabular}{|l|l|l|l|}
\hline Condition & Mean & SD & p \\
\cline { 1 - 3 } Affected & 55.86 & 8.0 & \\
\cline { 1 - 3 } Non-affected & 64.04 & 7.2 & \multirow{2}{*}{0.225} \\
\hline
\end{tabular}

$* p>0.05$ (for a two-tailed test)

Table 3. Mental health wellbeing of the affected and non-affected people measured by $\mathrm{GHQ}$

\begin{tabular}{|l|l|l|l|}
\hline Condition & Mean & SD & p \\
\cline { 1 - 3 } Affected & 27.72 & 3.4 & \\
\cline { 1 - 2 } Non-affected & 29.42 & 4.4 & \multirow{2}{*}{0.03} \\
\hline
\end{tabular}

$* p<0.05$ (for two tailed test)

\section{RESULTS}

Among the total participants, the mean age of the affected participants was 30.1 years $(\mathrm{SD}=11.09)$ and the non-affected was 28.98 year $(S D=5.17)$. Table 1 shows that about $4 \%$ people in the affected site earned daily 5 USD and above, whereas the rate was $24 \%$ in the non-affected, on the other hand $24 \%$ of affected people earned less than 2 USD per day, that is, only $16 \%$ in the non-affected group.

Table 2 shows the average coping score of the affected and nonaffected people. The COPE score for the affected group ranged from 33 to 71 (mean 55.86), and for the non-affected group, it was 38 to 84 (mean 64.04). However, although the affected people scored higher mean, the difference was not statistically significant.

Table 3 shows that people who were not affected by riverbank erosion scored higher than those of river bank affected group.

\section{DISCUSSION}

This was one of the first few studies that compared the mental health and coping of the river erosion affected people with the non-affected people in Bangladesh. We observed that the mental health wellbeing of the people who were affected by river bank erosion was poor in comparison to the nonaffected group that was consistent with the previous researches in other countries (Munro et al., 2017; Doherty \& Clayton, 2011; Everly, Perrin and Everly, 2008; Diaz et al. 2006). It may have occurred due to the fact that river bank erosion uprooted them, and they were forced to adapt themselves in a new environment with minimum or no economic source to sustain. Moreover, river erosion exposure can elicit pre-existing psychological distress, somatic complaints, sleep problems and psychosocial behavioural problems (Neria et al., 2009; Norris \& Elrod, 2006; Norris et al., 2002). Though these people are vulnerable to physical and mental health problems, they face severe lack of medical facilities and treatment as the health care infrastructures engulfed by the river and new settlement takes time to reconstruct their medical facilities. People have to travel longer distances than before and bear extra cost for medical treatment. Sometimes, medicine shops are also eroded and it becomes impossible to provide first aid treatment to the victims (Das et al., 2017). Many people needed to schedule physician visits for disaster related conditions. Telemedicine and telepsychiatry can be a good option to ensure early treatment for the victims of river erosion.

Displaced populations face stressors related to the disruption of their social networks, separation from family and social isolations. To adapt in new environment, people use problem solving and emotion coping mechanisms. Besides, displaced people maintain pre-existing social networks at distance. These social ties may serve as a source of substantial resilience or capacity to cope with adverse events (Torres et al., 2017). Moreover, this resettlement process created short- and longterm psychosocial stress. Overall, the study found that the mental health of river bank erosion affected people was poor 
in comparison to the non-affected group. This finding was consistent with the previous researches in different countries (Munro et al. 2017; Doherty \& Clayton, 2011; Everly, Perrin and Everly, 2008; Diaz et al., 2006; Aslam \& Kamal, 2015). Evidence indicates that natural disasters influence the burden of mental health consequences in the affected population. When disasters strike the community and human population, physical harm and losing resources is accompanied by psychological distresses among the survivors (Shultz, 2013). However, the stresses were reported to be linked with stress disorders, anxiety, depression, somatic complaints, sleep disorders and other psychosocial behavioural problems (Neria et al., 2009; Norris \& Elrod, 2006; Norris et al., 2002; Helgeson et al., 2012; Hutton and Haque, 2003). Moreover, the psychological resilience helps to cope with the losses and increases the ability to bounce back. The river erosion affected people showed better adaptability due to the need to resettle themselves in the new environment and their perception that river erosion is not an impending danger to their livelihoods and well-being (David \& Hutton). The affected people are more active in coping, planning, suppression of competing activities, restraint coping and seeking of social support, which conform with some other research findings. People having strong previous mental health makeup respond to river erosion more confidently, and accessing necessary resources (Gil- Rivas \& Kilmar, 2016; Aldrich \& Sawada, 2015; Bankoff, 2007) made them more resilient to the disaster. In stressful situations, people focus on versatile coping (Baqutayan, 2015), and human behaviour is not only a function of environmental demands, but also shaped by organizing daily activities, and fixing difficulties and problems (Norris, Stevens, Pfefferbaum, Wyche and Pfefferbaum, 2008). Government should take initiative for the psychological issues regarding the disaster.

\section{LIMITATION OF THE STUDY}

During the interpretation of the study findings, we need to consider a few limitations. This was a cross sectional study with a small number of participants that limits us to commit it as the general scenario of the country. Moreover, coping mechanism is diverse and people use different coping strategies at different times that need in depth interviews with the participants. The study was conducted in a specific area in the country that may not be representative of the whole country. According to us, a large scale multicentre study involving all the divisions of the country will be more helpful.

\section{CONCLUSION}

Crisis from natural disasters represent particularly complex experiences that diminish the quality of life by impacting both individual and community support systems, causing distresses and devastation of resources. River erosion is a significant stressor for mental health and wellbeing. We need to evaluate the mental health and coping skills of the river bank affected people in a larger scale and mental health support system need to integrate in the existing health care system.

\section{ETHICAL DECLARATION}

We performed the study in accordance with the ethical standards of the 1964 Helsinki Declaration. Informed consent was obtained from all individual participants involved in the study. Consent to participate in the research has been given freely and without coercion. Subjects have the capacity to understand the research project. Consent of the research subject has not been influenced by financial inducement, improper pressure or any form of misrepresentation.

\section{CONFLICT OF INTEREST}

None to declare.

\section{AUTHORS' CONTRIBUTIONS}

All authors contributed to this work equally.

\section{FUNDING SOURCE}

Self-funded by the researchers.

\section{DATA AVAILABILITY}

The dataset has been shared with the editorial office of the journal. 


\section{REFERENCES}

Aldrich, D. P., \& Sawada, Y. (2015). The Physical and Social Determinants of Mortality in the 3.11 tsunami. Social Science \& Medicine, 124, 66-75.

Aslam, N., \& Kamal, A. (2015). Coping Strategies as a Predictors of Psychological Distress and Post Traumatic Growth among Flood Affected Individuals. Journals of Alcoholism and Drug Dependence, 3:181. Available at https://www.omicsonline. org/open-access/coping-strategies-as-a-predictors-ofpsychological-distress-and-post-traumatic-growth-amongflood-affected-individuals-2329-6488.1000181. php?aid=36528

Baqutayan, S. M. S. (2015). Stress and Coping Mechanisms: A Historical Overview. Mediterranean Journal of Social Sciences. 6(2). Available at https://www.ncbi.nlm.nih.gov/pubmed/29420257

Brooks, S., Amlot, R., Rubin, G. J., Greenberg, N. (2018). Psychological resilience and post-traumatic growth in disasterexposed organisations: overview of the literature. 1-5. Doi: 10.1136/jramc-2017-000876.

Carver, C.S., Scheier, M.F \& Weintraub, J.K. (1989). Assessing coping strategies: A theoretically based approach. Journal of Personality and Social Psychology, 56, 267-283.

Das, K. T., Haldar, S. K., Sarkar, D., Borderon, M., Kienberge, S. Gupta, I. D., Kundu, S. Guha \& Sapir, D. (2017). Impact of River Erosion: A case study. Disaster and Trauma Studies. 21 (2). Available at https://www.researchgate.net/publication/321823798_Impact_ of_Riverbank_Erosion_A_Case_Study

Diaz, J. O., Murthy, R. S. \& Lakshminarayana, R. (2006). Advances in Disaster Mental Health and Psychological Support. Voluntary Health Association of India Press. New Delhi India.

Doherty, T. J. \& Clayton, S. (2011). The Psychological Impacts of Global Climate Change. American Psychological Association, 66(4). 265-276. Doi: 10.1037/a0023141.

Everly, G. S., Perrin, P. \& Everly, G. S. (2008). Psychological issues in Escape, Rescue, and Survival in the wake of disaster. National Institute of Occupational Safety and Health, Pittsburgh, PA, USA.

Gil-Rivas, V. \& Kilmer, R. P. (2016). Building Community Capacity and Fostering Disaster Resilience. Journal of Clinical Psychology, 72, 1318-1332.
Goldberg, D. (1978). Manual of the General Health Questionnaire. Winndsor: NFER.

Government of Bangladesh. (2010). National Plan for Disaster Management, 2010-2015. Final version. Disaster Management Bureau Disaster Management \& Relief Division, Government of people's Republic of Bangladesh. (Online Accessed on 22-0112018 Available from https://www.preventionweb.net/english/ professional/policies/v.php?id=16676

Government of Bangladesh. (2013). Disaster Report 2013. Department of Disaster Management. Ministry of Disaster Management and Relief, Government of the People's Republic of Bangladesh.

Helgeson, J. Dietz, S., \& Hochrainer, S. (2012). Vulnerability to weather disasters: the choice of coping strategies in rural Uganda. Centre for Climate Change Economics and Policy Working Paper No. 107. Grantham Research Institute on Climate Change and the Environment. Available at https://papers.ssrn.com/sol3/papers. cfm?abstract_id=2191965

Hutton, D. \& Haque, C. E. (2003). Patterns of Coping and Adaptation Among Erosion Induced Displaces in Bangladesh: Implications for Hazard Analysis and Mitigation. Natural Hazards, 29. 405-421. Available at https://link.springer.com/ article/10.1023/A:1024723228041

International Federation of Red Cross and Red Crescent societies (IFRCS) (2011) World Disasters Report, 2001. Switzerland.

Ilyas, Q. S. M. \& Ayesha, M. (2002). Bengali version of Goldberg's General Health Questionnaire. Unpublished Manuscript. Department of Psychology, University of Dhaka, Dhaka.

Islam, M. F. \& Rashid, A. N. M. B. (2011). River Bank Erosion Displaces in Bangladesh: Need for Institutional Response and Policy Intervention. Bangladesh Journal of Bioethics. 2(2). 4-19. Available at https://www.banglajol.info/index.php/BIOETHICS/ article/view/9540.

Kaminsky, M., McCabe, O. L., Langlieb, A. M., \& Everly, G. S. (2007). An evidence-informed model of human resistance, resilience, and recovery: The Johns Hopkins' outcome-driven paradigm for disaster mental health services. Brief Treatment and Crisis Intervention, 7(1), 1-11. Available from: doi: 10.1093/brieftreatment/mhl015. 
Karatoreos, I. N., \& McEwen, B. S. (2013). Annual research review: The neurobiology and physiology of resilience and adaptation across the life course. The Journal of Child Psychology and Psychiatry, 54, 337-347. Available from: https://www.ncbi.nlm.nih. gov/pubmed/23517425

Keya, M. K., Begum, H. A. \& Haque, A. B. (2009). Mental Health of Arsenicosis Patients. International Journal of Cross-Cultural Studies, (1) 87-96.

Keya, M. K. \& Harun, S. M. R. (2007). Riverbank Erosion Induced Stress and Coping of Displaced Women in Bangladesh. Empowerment, (14) 17-30.

Lowe, S. R., Sampson, L., Gruebner, O., Galea, S. (2015). Psychological Resilience after Hurricane Sandy: The Influence of Individual - and Community - Level Factors on Mental Health after a Large-Scale Natural Disaster. PLOS ONE 10(5): e0125761. Available from https://doi.org/10.1371/journal.pone.0125761

Martin, U. (2015). Health after disaster: A perspective of psychological/health reactions to disaster. Journal of Cogent Psychology, 2(1). Available from https://doi.org/10.1080/2331190 8.2015 .1053741

Mohammady, M. A., Khan, M. A. and, Arya, A. R. M. (2012). Coping Strategies in relation to Mental Health. Journal of subcontinents Researches, 4 (11), 71-92.

Montazeri, A., Harirchi, A.M., Shariati, M., Garmaroudi, G., Ebadi, M., Fateh, A., 2003. The 12-item General Health Questionnaire (GHQ-12): translation and validation study of the Iranian version. Health Qual. Life Outcomes 4, 1-4.

Munro, A., Kovats, S., Rubin, J., Waite, T. D., Bone, A., Armstrong, B. (2017). Effect of evacuation and displacement on the association between flooding and mental health outcomes: a cross-sectional analysis of UK survey data. The Lancet Planetary Health, 4(1). 134141. doi.org/10.1016/S2542-5196 (17)30047-5.

Neria, Y., Galea, S., Norris, F. H. (2009). Mental health and disaster. United State, NY: Cambridge University Press. ISBN: 978-0-52188387-0 (hbk.).

Norris, F. H., Stevens, S. P., Pfefferbaum, B., Wyche, K. F., \& Pfefferbaum, R. L. (2008). Community resilience as a metaphor, theory, set of capacities and strategy for disaster readiness. American Journal of Community Psychology, 41, 127-150.
Norris, F. H., \& Elrod, C. L. (2006). Psychosocial consequences of disaster: A review of the literature. In F. Norris, S. Galea, M. Friedman, \& P. Watson (Eds.), Methods for disaster mental health research. 20-42. New York: Guilford Press.

Norris, F., Friedman, M.J., Watson, P. J., Byrne, C. M., Diaz, E., \& Kaniasty, K. (2002). 60,000 victims speak: Part I, An empirical review of the literature, 1981-2001. Psychiatry, 65, 207-239.

Ruddick, F. (2013). Promoting mental health and health. Nursing Standard. 27 (24) 35-39.

Sousa, A. D., \& Shrivastava, A. (2017). Resilience among people who face natural disaster. Journal of Psychiatrists Association of Nepal, 4(1), 1. doi:10.3126/jpan.v4i1.16735.

Walter, J. (Ed.). (2001). World Disasters Report 2001- Focus on recovery (Rep. No. ISBN 92 9139-075-5). Switzerland, Geneva: International Federation of Red Cross and Red Crescent Societies.

World Health Organization, Disasters and mental health (2017). Retrieved from http://www.searo.who.int/bangladesh/ disastersandmentalhealth/en/.

Yeasmin, A. \& Islam, M. N. (2011). Changing trends of channel pattern of the Ganges-Padma river, International Journal of Geomatics and Geosciences, 2: 669-675. Available from: http:// www.ipublishing.co.in/jggsvol2no22011abstracts.html. 